\title{
EXAMINING MULTI-LEVEL POVERTY-CAUSING FACTORS OF FARM HOUSEHOLD
}

\author{
Yuewen Jiang ${ }^{1,2,3}$, Yanhui Wang ${ }^{1,2,3, * \text {, Wenping Qi }}{ }^{1,2,3}$ \\ ${ }^{1}$ Beijing Key Laboratory of Resource Environment and Geographic Information System, Capital Normal University, Beijing 100048 , \\ China \\ ${ }^{2}$ Ministry of Education Key Laboratory of 3-Dimensional Information Acquisition and Application, Capital Normal University, \\ Beijing 100048, China \\ ${ }^{3}$ State Key Laboratory Incubation Base of Urban Environmental Processes and Digital Simulation, Capital Normal University, \\ Beijing 100048, China
}

Commission IV, IC WG IV/III, WG IV/4

KEY WORDS: Poverty-causing factors, Multi-level linear model (MLM), Geo-detector

\begin{abstract}
:
In view of the current research on the factors of poverty at home and abroad, most of them have less background effects on scale and the mechanism. This study uses a multi-level linear regression model and a geographic detector to jointly detect the poverty influencing factors in the study area. This study mainly draws the following three conclusions: (1) There are background effects on the scale of the poverty-stricken factors in the study area, and the background effects have a great impact. (2) At different scales there are significant poverty-stricken factors. (3) Different research methods lead to differences in research results.
\end{abstract}

\section{INTRODUCTION}

The eradication of poverty is an important dimension of the UN's 2030 sustainable development goals and an important guarantee for the task of building a well-off society in an allround way. China is the largest developing country in the world, and its poverty reduction efforts have a pivotal impact on global poverty reduction (Liu, et al., 2016). Farmers' poverty has always been a key consideration for the Chinese government to formulate a series of poverty alleviation policies (Zhou et al., 2018). In order to solve a series of poverty problems, it is crucial to accurately explore the causes of poverty. So far, many experts and scholars at home and abroad have explored the factors of poverty from different angles (Carneiro et al., 2016; Wang \& Qian, 2017; Aristondo, 2018). However, on the one hand, most research methods use traditional linear regression models to explore poverty factors from a single scale (Ibrahim et al., 2016; Du et al., 2018; Guo Et al., 2018), not considering the geographical background factors of the research object. On the other hand, due to data acquisition restrictions and other reasons, most studies are based on provinces, cities, counties, villages, etc. Geographic unit scale as the evaluation object (Wang \& Chen, 2017; Liu et al., 2018; Michalek \& Madajova, 2019), and the detection of poverty-reducing factors from a more elaborate scale is more conducive to the precision of poverty alleviation. In view of this, this paper selects Fugong County of China as the research area and takes the poor households as the research unit. From the perspective of the new research of the individual effects and background effects of the comprehensive detection of influencing factors, the multi-level linear model and the geo- detector are used to achieve a more accurate detection of the cause of poverty.

\section{RESEARCH AREA AND DATA}

This paper selects Fugong County of Yunnan Province as the research area. Fugong County is one of the key counties for poverty alleviation in the country. It has has a wide range of poverty, a high proportion of poverty, a deep degree of poverty and a great difficulty in getting rid of poverty. The poverty problem in Fugong County needs to be solved urgently. The data in this paper are survey data of poor farmers and basic statistics of villages. A total of 1,000 valid samples were taken from the survey data of farmers, covering 57 villages in the county.

\section{RESEARCH METHODS}

\subsection{Index system construction}

Based on the actual situation of the study area, referring to the existing related research, considering the typicality, representativeness and accessibility of the indicators, a total of 21 impact factors (including household level factors and village level factors) of 9 dimensions are selected to constitute a candidate set of indicators. Then, the coefficient of variation method and the complex correlation coefficient method are used to screen all the indicators in the candidate set, and finally 20 influencing factors are retained to participate in the calculation. The constructed indicator system and screening results are shown in Table 1 .

\footnotetext{
* Corresponding author. Email: huiwangyan@ @sohu.com
} 


\begin{tabular}{|c|c|c|c|}
\hline Type & Variable & Variable interpretation & $\begin{array}{l}\text { Coefficient of } \\
\text { variation }\end{array}$ \\
\hline Ident variable & $Y \_$poverty & Poverty level & - \\
\hline \multirow{2}{*}{$\begin{array}{l}\text { ographical } \\
\text { ocation }\end{array}$} & $X_{1}$ & Distance from the main road & retain \\
\hline & $X_{2}$ & Road access type & retain \\
\hline \multirow{4}{*}{$\begin{array}{l}\text { Family } \\
\text { racteristics }\end{array}$} & $X_{3}$ & Ratio of healthy family members (\%) & retain \\
\hline & $X_{4}$ & Ratio of family labor force $(\%)$ & retain \\
\hline & $X_{5}$ & Ratio of population with education below high middle school excepting students (\%) & retain \\
\hline & $X_{6}$ & Ratio of non-compulsory education students in family $(\%)$ & retain \\
\hline \multirow{2}{*}{ ial Security } & $X_{7}$ & $\begin{array}{l}\text { Ratio of population enrolled in the new rural cooperative medical insurance of China in } \\
\text { the family }(\%)\end{array}$ & retain \\
\hline & $X_{8}$ & $\begin{array}{l}\text { Ratio of population enrolled in urban and rural basic pension insurance in the family } \\
\qquad(\%)\end{array}$ & retain \\
\hline $\begin{array}{l}\text { conomic } \\
\text { relopment }\end{array}$ & $X_{9}$ & Per capita annual income of family (yuan) & retain \\
\hline \multirow{4}{*}{$\begin{array}{l}\text { ographical } \\
\text { vironment }\end{array}$} & $Y_{1}$ & Terrain relief & retain \\
\hline & $Y_{2}$ & Altitude & retain \\
\hline & $Y_{3}$ & Slope & retain \\
\hline & $Y_{4}$ & Per capita cultivated land area & retain \\
\hline \multirow{2}{*}{ rastructure } & $Y_{5}$ & Road access ratio $(\%)$ & retain \\
\hline & $Y_{6}$ & Education (whether there is a primary school in the village, yes $=1$, no=0) & retain \\
\hline \multirow{2}{*}{ or situation } & $Y_{7}$ & Ratio of village labor force $(\%)$ & retain \\
\hline & $Y_{8}$ & Proportion of migrant workers in the village $(\%)$ & retain \\
\hline \multirow{2}{*}{ ial Security } & $Y_{9}$ & $\begin{array}{l}\text { Ratio of population enrolled in the new rural cooperative medical insurance of China in } \\
\text { the village }(\%)\end{array}$ & retain \\
\hline & $Y_{10}$ & $\begin{array}{l}\text { Ratio of population enrolled in urban and rural basic pension insurance in the village } \\
\qquad(\%)\end{array}$ & retain \\
\hline \multirow{2}{*}{$\begin{array}{l}\text { conomic } \\
\text { velopment }\end{array}$} & $Y_{11}$ & Per capita annual income of the village (yuan) & retain \\
\hline & $Y_{12}$ & Collective income of the village (yuan) & retain \\
\hline
\end{tabular}

Tab.1 Indicators of household-village

Note: The dependent variable is the poverty level (Y), expressed as the per capita income level. According to the national poverty line and relevant documents of the study area, the following grades are divided into: 1067 yuan (including 1067 yuan) for absolute poverty, assigned value 5; 1067-2300 yuan for deep poverty, assigned value 4; 2300-2800 yuan for medium Poverty, assigned value 3; 2800-3500 yuan for mild poverty, assigned value 2; more than 3,500 yuan for poverty, assigned value 1 . For the entry type indicator, the scoring system is adopted, the asphalt road is assigned value 1 , the cement road is assigned value 0.75 , the sand road is assigned value 0.5 , and the ordinary soil road is assigned value 0.25 


\subsection{Introduction to the method}

In this paper, two methods are used to detect the povertyreducing factors in the study area, namely multi-level linear regression model and geographic detector. Multi-level linear regression model is a statistical method for processing data with nested structure. It can effectively solve the problem of background effect and analyze the influence of independent variables on dependent variables from different levels (Raudenbush \& Bryk, 2002; Wang et al., 2019). Geo-detectors can detect spatial stratification heterogeneity of variables and detect how a factor interprets the spatial differentiation of the variable. Because the data in the study area is nested on the scale, that is, the household is embedded in the village, and there may be spatial differences in the poverty factors of farmers in different villages. Therefore, both methods are applicable to this study. At the same time, two methods are used for research. On the one hand, the results can be mutually verified. And on the other hand, it can be more comprehensive to detect the significant poverty factors. The principle introduction of the two methods is shown in Table 2.

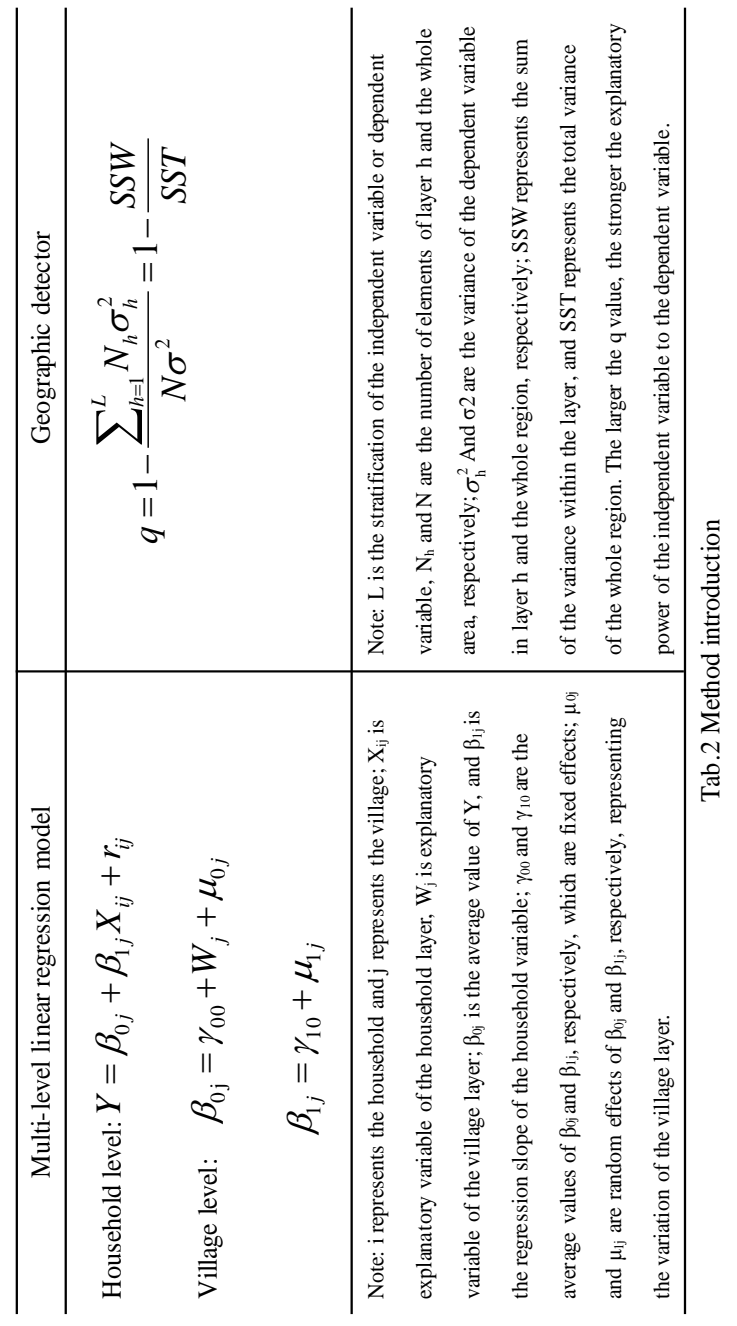

\section{RESULTS AND ANALYSIS}

Before constructing a multi-level model with independent variables, construct a null model (without any independent variables), and combine the variance ratio calculation formula to detect whether there is a scale background effect on the poverty-reducing factors of the research object. Table 3 shows the estimation results of the null model and the calculation results of the variance ratio and the q statistics calculated by the administrative village as a partition with the geo-detector. The results are shown in Table 3.

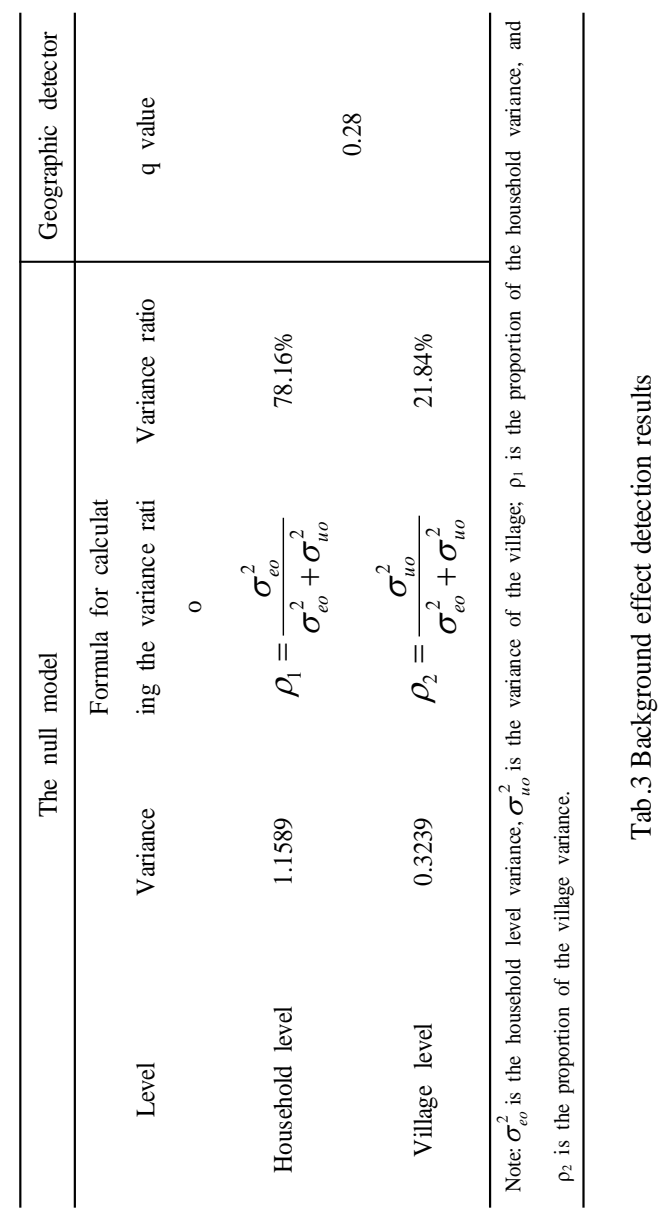

From the calculation results of the variance ratio in Table 3, the household-level variance ratio is $78.16 \%$, indicating that the household-level factors are dominant. And the village-level variance ratio is $21.84 \%$, indicating that the village-level factor cannot be ignored. From the q value of the geo-detector, the village factor is $28 \%$. On the whole, there is a background effect on the scale of the poverty-stricken factors in the study area, which needs to be detected by multi-level linear regression model and geographic detector.

The household level factor is added to the first level of the multi-level model, and the village level factor is added to the second level of the multi-level model to explore the impact of the multi-level scale influencing factors on poverty. Calculate the $\mathrm{q}$ value directly using the geo-detector. The results are shown in Table 4.

Analysis of results: From the data in Table 4, (1) it is found that the significant influencing factors obtained by the multi-level linear model and the geo-detector are consistent in general, indicating that these two methods have certain rationality in detecting the significant poverty-reducing factors. However, the two methods show different degrees of significance in the estimation results, which may be related to the different methods of estimation of them. It can be verified by field research. It can be seen that in the research process, it is necessary to use different methods for comparison, which is beneficial to improve the accuracy of the results. (2) The 
common household-level significant factors obtained by the two methods are $\mathrm{X}_{4}, \mathrm{X}_{8}$ and $\mathrm{X}_{9}$, with the exceptions $\mathrm{X}_{2}$ and $\mathrm{X}_{5}$. (3) The main poverty-reducing factors obtained by the two methods are: $\mathrm{Y}_{1}, \mathrm{Y}_{3}, \mathrm{Y}_{4}, \mathrm{Y}_{5}, \mathrm{Y}_{10}, \mathrm{Y}_{11}$, except that $\mathrm{Y}_{2}, \mathrm{Y}_{6}, \mathrm{Y}_{9}$ $\mathrm{Y}_{12}$ is not detected as significant factors by two methods.

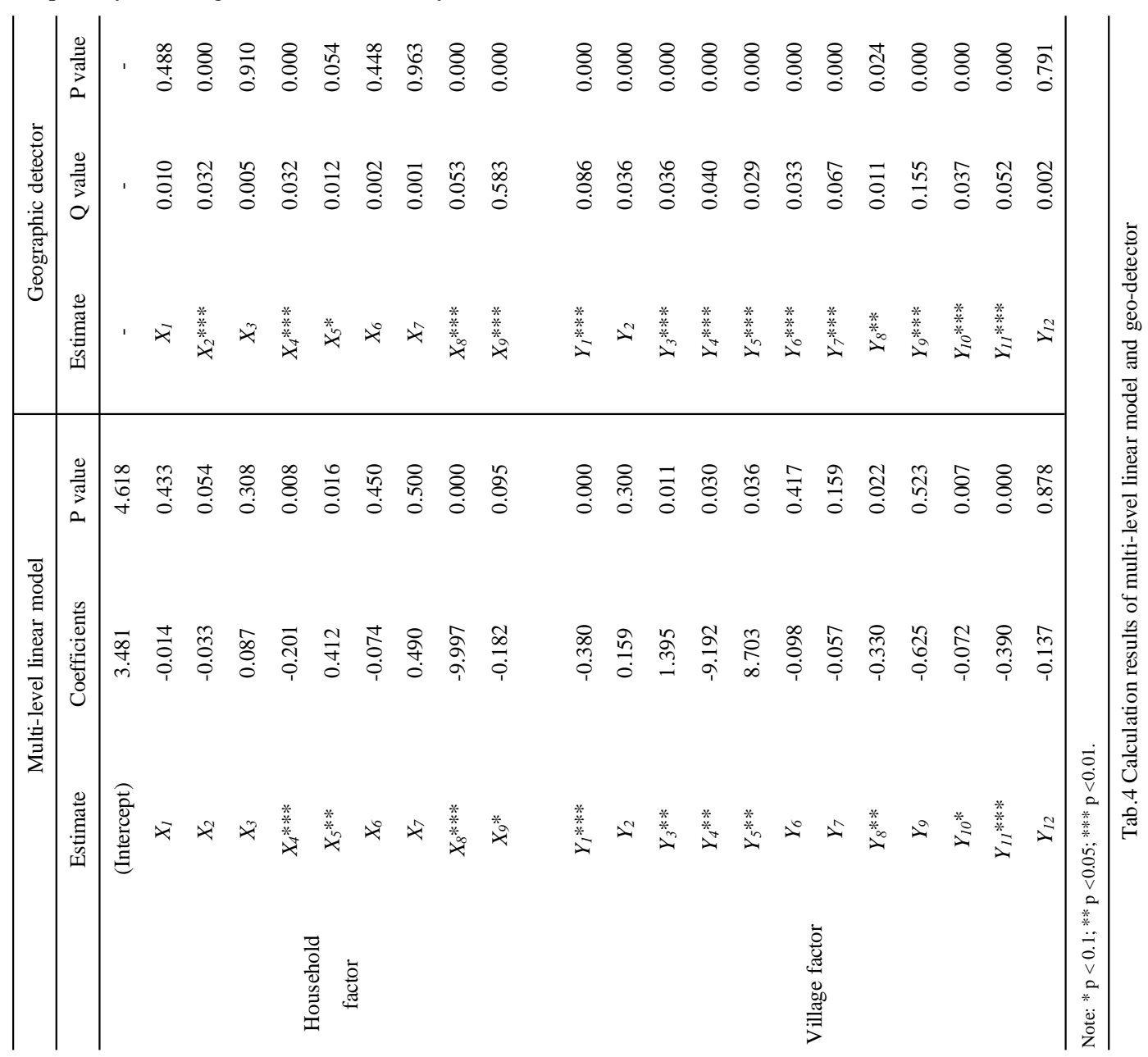

\section{CONCLUSION}

The comparison test results of two detection methods show that: (1) There are scale effects of the poverty alleviation factors in the study area, and the background effect has a large impact and can be studied using a multi-level model.; The q value of the geo-detector of household poverty level is 0.28 . Both methods indicate that about $25 \%$ of poverty-stricken households are caused by village-level factors. (2) Significant poverty factors at different scales are different. The main factors causing poverty at the household level are: ratio of family labor force, ratio of population enrolled in urban and rural basic pension insurance in the family, and per capita annual income of family; the significant poverty factors at the village level are: slope, per capita arable land, access rate and so on. At the household level, the detection results of the two methods are basically the same. At the village level, there are some differences in the detection results of the two methods, mainly because the sample size of the village level indicators is small and the variable types are complex. (3) The difference in research results due to different research methods indicates that it is necessary to use two or more methods to improve the accuracy of the research results. Field investigation is needed to verify the suitability of the method and the reliability of the results.

\section{REFERENCES}

Aristondo O., 2018: Poverty Decomposition in Incidence, Intensity and Inequality. A Review. Hacienda Publica Espanola-Review of Public Economics, (225): 109-130.

Carneiro D. M., Bagolin $\quad$ I. P., Tai S. H. T., 2016: Poverty determinants in Brazilian Metropolitan Areas from 1995 to 2009. Nova Economia, 26(1): 69-96.

Du G. M., Jiang Y. Y., Sun X. B., et al., 2018: County level poverty pattern and influencing factors in Heilongiiang Province. Research of Agricultural Modernization, 39(3): 460467.

Guo Y. Q., Chang S. S.; Sha. F., Yip PSF., 2018: Poverty concentration in an affluent city: Geographic variation and correlates of neighborhood poverty rates in Hong Kong. Plos One, 13(2). 
Ibrahim I., Baiquni M., Ritohardoyo S., et al., 2016: Analysis of the factors affecting the poverty in rural areas around gold mine areas in West Sumbawa Regency. Journal of Degraded and Mining Lands Management, 3(3): 585-594.

Liu C., Huang J., Gong J., et al., 2018: Provincial Difference and Influencing Factors of Targeted Poverty Alleviation in China. Scientia Geographica Sinica, 38(7): 1098-1106.

Liu Y. S., Zhou Y., Liu J. L., 2016: Regional differentiation characteristics of rural poverty and targeted poverty alleviation strategy in China. Bulletin of Chinese Academy of Sciences, 31(3): 269-278.

Michalek A., Madajova M. S., 2019: Identifying regional poverty types in Slovakia. Geojournal, 84(1) : 85-99.
Wang Y. H., Chen Y. F., 2017: Using VPI to Measure PovertyStricken Villages in China. Social Indicators Research, 133(3): 833-857.

Wang Y. H., Qian L. Y., 2017: A PPI-MVM model for Identifying Poverty-Stricken Villages: A Case Study from Qianjiang District in Chongqing, China. Social Indicators Research, 130(2): 497 - 522.

Zhou Y., Guo Y. Z., Liu Y. S., et al., 2018: Targeted poverty alleviation and land policy innovation: Some practice and policy implications from China. Lsnd Use Policy, 74: 53-65. 